\title{
ANÁLISE DA APRENDIZAGEM BASEADA EM PROBLEMAS NA EDUCAÇÃO PROFISSIONAL EM SAÚDE
}

\author{
Verônica Filter de Andrade ${ }^{1}$, José Pedro Schardosim Simão² \\ ${ }^{1}$ Curso de Pós-Graduação em Docência para Educação Profissional e Tecnológica, Instituto \\ Federal de Santa Catarina, Ararangúa, SC,, Brasil. \\ 2 Prof ${ }^{a}$, Instituto Federal de Santa Catarina, Ararangúa, SC, Brasil. \\ Email para correspondência: veronicafilter@gmail.com
}

\begin{abstract}
Resumo
Considerando as novas demandas na formação em saúde, muito se fala de metodologias que possibilitem inovar e agregar no ensino profissional. Com isso, esse estudo teve como objetivo analisar na produção científica acerca da Aprendizagem Baseada em Problemas na Educação Profissional em Saúde. Por meio de uma revisão bibliográfica, de caráter descritivo, nas bases de dados LILACS e SCIELO. A coleta pelas fontes ocorreu no mês de outubro de 2019, a partir do cruzamento dos descritores: Aprendizagem Baseada em Problemas e Educação em Saúde, nas bases de dados. Os artigos foram lidos criteriosamente na íntegra e selecionados, compondo a amostra por 5 artigos. Levando-nos a concluir que a Aprendizagem Baseada em Problemas é uma excelente ferramenta metodológica, que contribui para formação de habilidades e competências dos profissionais de saúde para a realidade social.
\end{abstract}

Palavras-chave: Aprendizagem Baseada em Problemas. Educação em Saúde. Metodologia Ativa.

\begin{abstract}
Recognize as new demands in health education, much is said about methodologies that make it possible to innovate and add to professional education. Thus, this study aimed to analyze the scientific production on Problem-Based Learning in Professional Health Education. Through a descriptive bibliographic review, in the LILACS and SCIELO databases. The collection by the sources occurs in the month of October 2019, from the crossing of the descriptors: Problem-Based Learning and Health Education, in the databases. The articles were carefully read in full and selected, making up the sample for 5 articles. Leading us to conquer that Problem Based Learning is an excellent methodological tool, which contributes to the formation of skills and competences of health professionals for the social reality.
\end{abstract}


Keywords: Problem-Based Learning. Health Education. Active Methodology.

\section{Introdução}

Novas formas de trabalhar o ensino em saúde, vem sendo discutidas por diversos autores e estudiosos, visto a necessidade de se desenvolver melhores práticas profissionais. Essas questões procuram romper o modelo pedagógico tradicional e conservador, onde o aluno é um receptor passivo no ensino-aprendizagem. (FREITAS et al., 2015)

Mitre et al. (2008) referem que o grande desafio do século está em desenvolver a educação com uma visão do todo, por meio da autonomia individual junto à consciência coletiva. Além disso, se busca um método inovador e eficiente capaz de tal função.

Cyrino e Toralles-Pereira (2004) afirmam também, que a educação moderna deve valorizar a equidade, a qualidade da assistência, a eficiência e a relevância do trabalho em saúde, valorizando recuperar as dimensões essenciais do cuidado. Modernizar e inovar a educação é necessário para acompanhar as transformações no mundo moderno e o processo de mudança da educação profissional em saúde, diante dessa nova pedagogia, conta com a metodologia ativa como instrumento importante para atingir esse objetivo.

Freitas et al. (2015) ressaltam que os profissionais de saúde devem conseguir agir na resolução de problemas e responder as reais demandas da sociedade. E a metodologia ativa, por meio da Aprendizagem Baseada em Problemas (ABP) tem contribuído e potencializado essas ações.

Justifica-se essa pesquisa, devido à importância de se aplicar por meio da metodologia ativa a Aprendizagem Baseada em Problemas, como instrumento atual de modificar o saber-fazer. Possibilitando por meio dessa estratégia pedagógica ganhar habilidades e competências importantes na prática profissional. Com isso, a questão norteadora deste estudo foi como a Aprendizagem Baseada em Problemas contribui com a formação na Educação Profissional em Saúde?

Com base nessas considerações, o presente estudo contribuirá para uma abordagem metodológica estratégica e inovadora. Além, de discutir a ABP como um método para permitir mudanças na educação profissional e mobilizar o ensinar e o aprender. Assim, o objetivo principal desta investigação é analisar 
na produção científica acerca da Aprendizagem Baseada em Problemas na Educação Profissional em Saúde.

\section{Metodologia}

O presente estudo constitui uma revisão bibliográfica de caráter descritivo das práticas de Ensino em Saúde com enfoque na Aprendizagem Baseada em Problemas. A coleta pelas fontes que versam sobre o assunto da pesquisa ocorreu no mês de outubro de 2019.

Primeiramente foram selecionados os descritores, definidos a partir da terminologia em saúde consultada nos Descritores em Ciências da Saúde (DECS-BIREME), os quais foram "Aprendizagem Baseada em Problemas" e "Educação em Saúde". Os artigos foram selecionados por meio do cruzamento dos dois descritores nas bases de dados: LILACS (Literatura Latino-Americana e do Caribe em Ciências da Saúde) e SCIELO (Scientific Eletronic Library Online).

Na segunda etapa, foram incluídas publicações do tipo artigo com textos completos, disponíveis eletronicamente, nos idiomas Português, Inglês ou Espanhol, publicados no período de 2014 a 2019, cujo tema principal correspondesse a Aprendizagem Baseada em Problemas na Educação em Saúde. Foram excluídos da amostra, toda a produção duplicada, artigos indisponíveis na íntegra, bem como estudos que não abordassem a temática relevante ao alcance do objetivo deste estudo.

Após a busca nos bancos de dados, os artigos foram lidos criteriosamente na íntegra e selecionados. A amostra definitiva para análise desta revisão foi composta por 5 artigos, que se adequavam ao objetivo proposto e aos critérios de elegibilidade previamente definidos. É importante destacar que os aspectos éticos foram respeitados no que se refere à citação dos autores selecionados.

\section{Resultados e Discussão}

A análise da produção bibliográfica sobre a temática da Aprendizagem Baseada em Problemas na Educação em Saúde resultou em 15 artigos, por meio do cruzamento dos descritores: Aprendizagem Baseada em Problemas e Educação em Saúde, como apresenta a Tabela 1. 
$\mathrm{Na}$ base de dados LILACS foram encontrados 12 estudos, dos quais 9 foram excluídos por não contemplarem aspectos relevantes à temática da pesquisa. Na SCIELO foram achados um total de 3 artigos, destes, um foi excluído por corresponder a obra duplicada entre si. Ao final, foram recuperados, examinados e selecionados 5 estudos que compuseram a amostra.

A Tabela 2 apresenta a identificação dos artigos selecionados nesta revisão.

A Tabela 3 exibe o objetivo, metodologia e a conclusão dos artigos selecionados neste estudo.

No estudo de Mello et al. (2014) as metodologias ativas de aprendizagem, como a Aprendizagem Baseada em Problemas tem apresentado evidências positivas na educação em saúde no ensino superior. Pois, por meio dessa estratégia de ensino forma-se profissionais, com habilidades e competências além do domínio técnico-científico. E que se tornam capazes de criar, planejar, implementar e avaliar políticas e ações em saúde para a população. Sendo utilizadas com o propósito de que estudantes adquiram o conhecimento de forma significativa e não meramente mecânica.

O estudo descritivo de Guedes-Granzotti, et al. (2015), mostram a utilização de Metodologias Ativas na formação do profissional Fonoaudiólogo. Que por meio de situações problemas encontram respostas de forma ativa e autônoma. Formando assim, profissionais resolutivos, competentes para atuar de acordo com as práticas de Saúde Pública do País. Destacam ainda, que a construção da aprendizagem e problematização devem ser condizentes com a realidade que o profissional irá encontrar em sua prática clínica.

Costa et al. (2015) refletiram sobre as perspectivas contemporâneas do ensino e aprendizagem na formação em saúde e de enfermagem, a partir do uso da simulação como método ativo. Consideraram que essa metodologia possibilita construir novas formas de ensinar em saúde. Visto que, nas experiências em situações simuladas, os alunos e professores participam efetivamente do processo de ensino-aprendizagem. Os resultados contribuem ainda para a aquisição de novos saberes, e para uma formação mais próxima das necessidades exigidas pela sociedade atual. 
Tabela 1: Base de Dados

\begin{tabular}{cccc}
$\begin{array}{c}\text { Base de } \\
\text { Dados }\end{array}$ & Encontrados & Excluídos & Selecionados \\
LILACS & 12 & 9 & 3 \\
SCLIELO & 3 & 1 & 2 \\
Total & 15 & 10 & 5 \\
\hline \multicolumn{4}{c}{}
\end{tabular}

Tabela 2: Identificação da Amostra

\begin{tabular}{|c|c|c|c|}
\hline № & Título & Periódico & Autor/Ano \\
\hline 1 & $\begin{array}{l}\text { Metodologias de Ensino e } \\
\text { Formação na Área da Saúde: } \\
\text { Revisão de Literatura }\end{array}$ & $\begin{array}{l}\text { Rev. } \\
\text { CEFAC }\end{array}$ & $\begin{array}{l}\text { Mello, Alves, Lemos, } \\
2014\end{array}$ \\
\hline 2 & $\begin{array}{c}\text { Situação-Problema como } \\
\text { disparador do Processo de } \\
\text { Ensino-Aprendizagem em } \\
\text { Metodologias Ativas de } \\
\text { Ensino }\end{array}$ & $\begin{array}{l}\text { Rev. } \\
\text { CEFAC }\end{array}$ & $\begin{array}{l}\text { Guedes-Granzotti et al., } \\
2015\end{array}$ \\
\hline 3 & $\begin{array}{l}\text { O uso da simulação no } \\
\text { contexto da educação e } \\
\text { formação em saúde e } \\
\text { enfermagem: uma reflexão } \\
\text { acadêmica }\end{array}$ & $\begin{array}{l}\text { Rev. } \\
\text { Espaço } \\
\text { para a } \\
\text { Saúde }\end{array}$ & Costa et al., 2015 \\
\hline 4 & $\begin{array}{c}\text { Uma experiência de } \\
\text { integração ensino, serviço e } \\
\text { comunidade de alunos do } \\
\text { curso de graduação em } \\
\text { medicina na atenção básica } \\
\text { no município de Maceió-AL, } \\
\text { Brasil }\end{array}$ & $\begin{array}{l}\text { Revista } \\
\text { Ciência } \\
\text { Plural }\end{array}$ & Melo et al., 2017 \\
\hline 5 & $\begin{array}{l}\text { Metodologias Ativas de } \\
\text { Aprendizagem: caminhos } \\
\text { possíveis para inovação no } \\
\text { Ensino em Saúde }\end{array}$ & $\begin{array}{c}\text { Escola } \\
\text { Anna Nery }\end{array}$ & Macedo et al, 2018 \\
\hline
\end{tabular}

Tabela 3: Dados da Amostra

\begin{tabular}{|c|c|c|c|}
\hline № & Objetivo & Metodologia & Conclusão \\
\hline 1 & $\begin{array}{l}\text { Analisar a produção } \\
\text { científica nacional e } \\
\text { internacional acerca }\end{array}$ & $\begin{array}{l}\text { Revisão } \\
\text { literatura } \\
\text { sistemática }\end{array}$ & $\begin{array}{l}\text { A maior parte dos estudos } \\
\text { evidencia efeitos positivos } \\
\text { com a aplicação de novas }\end{array}$ \\
\hline
\end{tabular}


dos temas Educação

em Saúde,

Aprendizagem

Baseada em

Problemas

e

Aprendizagem

Significativa dos

últimos cinco anos estratégias de ensino e ainda, corrobora a necessidade de mudanças na educação em saúde no ensino superior. Além disso, a maioria das publicações se encontram no período de 2007 a 2009 e tem como eixo temático a Aprendizagem Baseada em Problemas.

\section{2}

Descrever de
processo
elaboração de uma
Situação-Problema e
de um Módulo de
aprendizagem e
refletir a importância
destes na formação
do Fonoaudiólogo

Refletir sobre as perspectivas atuais de ensino e aprendizagem no contexto

da formação em saúde e enfermagem a partir do uso da simulação enquanto metodologia ativa

Estudo descritivo
e reflexivo sobre o
processo de
elaboração de
uma Situação-
Problema

Estudo teórico reflexivo a partir do levantamento bibliográfico bibliográfico
0 problematizador construído a partir das SituaçõesProblema permite ao discente a busca de respostas diariamente, de forma ativa e autônoma, pela vivência e discussão do trabalho em equipe, dos aspectos biopsicossociais do indivíduo e das questões éticas na atuação profissional. Possibilitando assim a formação de profissionais resolutivos, competentes para aperfeiçoar seu conhecimento constantemente e de atuar em consonância com as práticas de Saúde Pública do País.

Reflete-se sobre a simulação enquanto método dinâmico e instrumento auxiliar de ensino-aprendizagem em saúde e enfermagem. Espera-se que as reflexões tecidas permitam a construção de conceitos que circundem a complexidade da formação em saúde e, em especial, a formação em enfermagem.

$\begin{array}{llll}\text { Apresentar } & \text { a } & \text { Relato } \\ \text { relevância da } & \text { IESC } \\ \text { experiência }\end{array} \quad$ de $\begin{aligned} & \text { A disciplina de IESC, } \\ & \text { portanto, pode ser adotada }\end{aligned}$




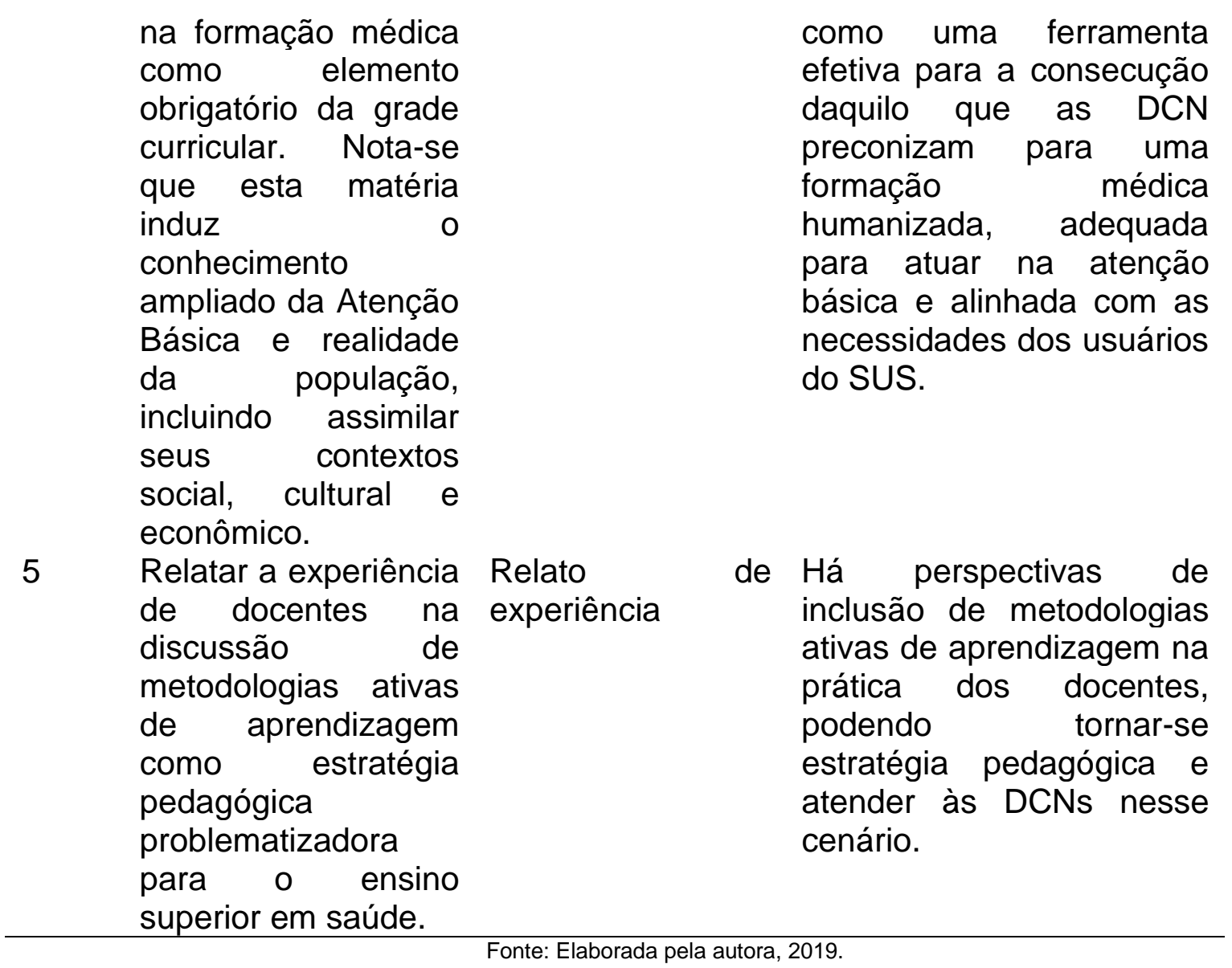

Melo et al. (2017) por meio da apresentação de resultado obtidos com o uso da metodologia ativa em uma vivência de acadêmicos no ensino médico nos mostra que adotar a Metodologia Ativa como ferramenta é efetivo no desenvolvimento de habilidades e saberes do aluno. Tendo em vista a possibilidade de confrontar teoria e prática, além de aproximar os estudantes da comunidade. Outro ponto de destaque é que com as novas Diretrizes Curriculares Nacionais, a formação médica passa a preconizar a humanização, a assistência generalizada, a saúde integral e a capacidade crítica e reflexiva. Sendo todos esses pontos desenvolvidos com o uso da metodologia dessa disciplina.

Macedo et al. (2018), relataram as experiências dos docentes com o uso das metodologias ativas de aprendizagem como estratégia pedagógica problematizadas para o ensino superior em saúde. A experiência proporcionou aos docentes conhecer, discutir e refletir sobre as metodologias ativas como estratégias inovadoras na educação e como forma de atender às Diretrizes Curriculares Nacionais. Pois a formação de profissionais em saúde críticos, 
reflexivos e transformadores de suas realidades está diretamente ligada às concepções pedagógicas.

\section{Conclusão}

Em resposta aos objetivos deste estudo, com base nos dados obtidos, constatou-se que o Ensino em Saúde vem sendo transformado por metodologias pedagógicas que são centradas no aluno, como a Abordagem Baseada em Problemas. Ressalta-se que todas as publicações evidenciaram efeitos positivos com a utilização dessa estratégia metodológica, proporcionando mais habilidades e competências aos alunos, que são fundamentais ao profissional da saúde.

Outro ponto de destaque é a necessidade de utilizar da ABP, de forma consciente e com aptidão dos profissionais docentes, fazendo necessária a capacitação dos professores para o uso das metodologias ativas. Além disso, há uma necessidade de integração entre docentes e instituições formadoras, visto que não se pode fazer um trabalho eficaz de forma isolada.

Apesar da escassez de trabalhos analisados com essa temática, esperase com os resultados desta pesquisa desperta novos estudos, no qual é necessário maiores publicações que fomentem a necessidade de mudanças na Educação em Saúde no ensino superior, de modo a promover as Metodologias Ativas, possibilitando uma continuidade na discussão do tema da Aprendizagem Baseada em Problemas.

\section{$5 \quad$ Referências}

ARAUJO, J. C. S. Fundamentos da metodologia de ensino ativa (1890-1931). 37ạ Reunião Nacional da ANPEd - 04 a 08 de outubro de 2015, UFSC - Florianópolis. Disponível em: <http://www.anped.org.br/sites/default/files/trabalho-gt02-4216.pdf>. Acesso em: 01 novembro 2019.

BRASIL. MINISTÉRIO DA EDUCAÇÃO. Diretrizes Curriculares Nacionais. Disponível em: <http://portal.mec.gov.br/component/content/article?id=12991>. Acesso em: 01 novembro 2019.

CECCIM, R. B.; FEUERWERKER, L. C. M. O Quadrilátero da Formação para a Área da Saúde: Ensino, Gestão, Atenção e Controle Social. Revista Saúde Coletiva, Rio de Janeiro, v.14, n.1, p. 41-65, jan./jun. 2004.

COLARES, K. T. P.; OLIVEIRA, W. Metodologias Ativas na formação profissional em saúde: uma revisão. Revista Sustinere, Rio de Janeiro, v.6, n.2, p. 300-320, jul./dez. 2018. 
COSTA, R. R. O. et al. O uso da simulação no contexto da educação e formação em saúde e enfermagem: uma reflexão acadêmica. Revista Espaço Para a Saúde, Londrina, v. 16, n. 1, p. 59-65, jan/mar. 2015.

CYRINO, E. G.; TORALLES-PEREIRA, M. L. Trabalhando com estratégias de ensinoaprendizado por descoberta na área da saúde: a problematização e a aprendizagem baseada em problemas. Caderno de Saúde Pública, Rio de Janeiro, v. 20, n.3, p. 780-788, mai./jun. 2004.

FARIAS, P. A.M. et al. Aprendizagem Ativa na Educação em Saúde: Percurso Histórico e Aplicações. Revista Brasileira de Educação Médica, v. 39, p. 143-158, 2015.

FREITAS, C. M. et al. Uso de metodologias ativas de aprendizagem para a educação na saúde: análise da produção científica. Trab. Educ. Saúde, Rio de Janeiro, v. 13, supl. 2, p. 117-130, dez. 2015.

GUEDES-GRANZOTTI, R.B. et al. Situação-problema como disparador do processo de ensino-aprendizagem em metodologias ativas de ensino. Rev. CEFAC., v. 17, p. 2081-2087. Nov./dez. 2015.

MACEDO, K. D.S. et al. Metodologias ativas de aprendizagem: caminhos possíveis para inovação no ensino em saúde. Escola Anna Nery, v. 22. 2018.

MELO B.C.; SANT'ANA G. A prática da Metodologia Ativa: compreensão dos discentes enquanto autores do processo ensino-aprendizagem. Revista ESCS, Distrito Federal, v.23, p.327-339, 2012.

MELO, B. T. et al. Uma experiência de integração ensino, serviço e comunidade de alunos do curso de graduação em medicina na atenção básica no município de Maceió-AL, Brasil. Revista Ciência Plural. v.3, p.69-80. 2017.

MELLO, C. C. B. et al. Metodologias de ensino e formação na área da saúde: revisão de literatura. Rev. Cefac., v.16, p. 2015-2028. nov./dez. 2014.

MENDES, T. M.C. et al. Interação ensino-serviço-comunidade no brasil e o que dizem os atores dos cenários de prática: uma revisão integrativa. Revista Ciência Plural. v. 4, p. 98-11. 2018.

MITRE, S. M. et al. Metodologias ativas de ensino-aprendizagem na formação profissional em saúde: debates atuais. Ciência \& Saúde Coletiva, Rio de Janeiro, v.13, supl. 2, p. 2133-2144, nov. 2008.

XAVIER et al. Analisando as metodologias ativas na formação dos profissionais de saúde: uma revisão integrativa. Sanare, Sobral, v.13, n.1, p. 76-83, jan./jun. 2014. 